\title{
Cooperation in an Uncertain World: For the Maasai of East Africa, Need-Based Transfers Outperform Account-Keeping in Volatile Environments
}

\author{
Athena Aktipis ${ }^{1}$. Rolando de Aguiar ${ }^{2}$ - Anna Flaherty ${ }^{2}$ - Padmini Iyer ${ }^{2}$. \\ Dennis Sonkoi $^{2} \cdot$ Lee Cronk $^{2}$
}

Published online: 3 May 2016

(C) The Author(s) 2016. This article is published with open access at Springerlink.com

\begin{abstract}
Using an agent-based model to study risk-pooling in herder dyads using rules derived from Maasai osotua ("umbilical cord") relationships, Aktipis et al. (2011) found that osotua transfers led to more risk-pooling and better herd survival than both no transfers and transfers that occurred at frequencies tied to those seen in the osotua simulations. Here we expand this approach by comparing osotua-style transfers to another type of livestock transfer among Maasai known as esile ("debt"). In osotua, one asks if in need, and one gives in response to such requests if doing so will not threaten one's own survival. In esile relationships, accounts are kept and debts must be repaid. We refer to these as "need-based" and "account-keeping" systems, respectively. Need-based transfers lead to more risk pooling and higher survival than account keeping. Need-based transfers also lead to greater wealth equality and are game theoretically dominant to account-keeping rules.
\end{abstract}

Keywords Need-based transfers · Account-keeping transfers $\cdot$ Risk pooling $\cdot$ Herd survival outcomes $\cdot$ Maasai . East Africa

\section{Introduction}

People everywhere have to deal with both predictable and unpredictable risks to their livelihoods. From modern day

Lee Cronk

lcronk@anthropology.rutgers.edu

Arizona State University, Tempe, AZ 85281, USA

2 Rutgers University, New Brunswick, NJ, USA humans grappling with uncertainties about health and employment, to Maasai pastoralist managing large herds in the face of potential drought, disease and theft, risk management is an important adaptive problem for humans around the world. Humans use many strategies to manage risk, including risk retention (accepting risk and absorbing losses), risk avoidance (reducing dependence on high variability outcomes), risk reduction (lowering the probability of or size of losses) and risk transfer (moving risk from one party to another) (Dorfman 2007). Risk transfer is of particular interest to social scientists because it is the only one of these methods that requires cooperation. One common form of risk transfer is risk-pooling (also referred to as risk-sharing). Here we use two different types of livestock transfer found among Maasai pastoralists in East Africa to examine whether some rules regarding such transfers lead to more risk-pooling and more effective risk management than others.

We build upon Aktipis et al. (2011), which used an agent-based model to examine the impact of stock friendships on risk-pooling and herd survival among East African pastoralists. That model was based specifically on the rules underlying Maasai stock friendships, which they refer to by their word for umbilical cord: osotua. The rules that govern osotua relationships are straightforward: Ask only if you are in need and only for what is needed, and give if you are able to do so without threatening your own survival. The model showed that pairs of herders that follow the rules of osotua had herds that survive longer in the face of occasional shocks than pairs that either engage in no livestock exchange or that exchange livestock probabilistically at rates derived from the osotua simulations. In this article, we expand our understanding of dyadic livestock exchange among Maasai by comparing osotua transfers with transfers Maasai refer to as esile, which translates simply as "debt" (Mol 1996). 
Maasai and other Maa-speaking pastoralists engage in several different types of livestock transfers, each of which follows a different set of rules. In addition to bridewealth payments, osotua, and esile, these include enkitaaroto, in which animals are put in someone else's herd but without a transfer of ownership, ketaaro or elipa, in which a milking cow is lent to a household in need, aitogaroo, in which a bull is lent for breeding purposes, and keitapashaki, in which animals are exchanged immediately, usually so that an individual can obtain a steer for ceremonial purposes (Perlov 1987:173-188).

Here we focus solely on osotua and esile, which have very different underlying logic and rules. When osotua partners transfer livestock, no debt is created, and it is inappropriate to talk about either debt or payment. Osotua partners have obligations to help one another, but the flow of goods and services between them does not need to be even roughly balanced over time (Cronk 2007). In transfers following the rules of esile, debt and repayment are of the essence. Esile means debt, and repayment is expected in the form of an animal at least as valuable if not more so than the one given. The repayment is referred to as elaata, which means to set free or untie a knot (Perlov 1987:184). If a debtor fails to repay, his creditor has the option of forgiving the debt but then referring to him henceforth as "Pasile": One whose debt I have forgiven. This type of construction, in which the prefix "pa" is used to indicate what a person has given or received, is common in Maa, but it is normally used in a positive way. For example, a man refers to his father-in-law as "Pakiteng," meaning "cow receiver." The use of the term "Pasile" essentially serves as a mild public reproach to those who fail to repay their debts. If debts are not repaid before the debtor dies, they are passed on to his heirs.

In principle, risk pooling could be accomplished via a variety of different resource transfer rules. Here we focus on two rules that can lead to the pooling of risk: osotua and esile. Because many pastoralists other than the Maasai also have rules that are equivalent to osotua and esile (Almagor 1978; Bollig 1998, 2010; Dyson-Hudson 1966; Flannery et al. 1989; Gulliver 1955), in an effort to generalize our terminology we will henceforth refer to these not by their Maa labels but rather as "need-based transfers" and "account keeping." Here we examine the underlying logic of both account keeping and need-based transfers and use an agent-based model to compare them in terms of their ability to enhance survival in volatile environmental conditions.

\section{Model}

This model is adapted from Aktipis et al.'s (2011) agent-based model of risk pooling among Maasai pastoralists. That model was constructed to examine herd survival in volatile ecological conditions characteristic of East African pastoralism (Dahl and Hjort 1976; Homewood 2008). Here, in addition to incorporating account-keeping rules, we also generalize this model by exploring a wider variety of ecological conditions. All parameter values and assumptions about resource volatility were initially drawn from Aktipis et al. (2011) and Dahl and Hjort (1976), but were then varied to investigate our questions of interest.

We used Netlogo software to model a population of two actors, each with a herd of finite size. Each actor represented a household/family of approximately six individuals and began with a herd of 70. Although Maasai and other Maa-speaking pastoralists keep a variety of different types of livestock (cattle, goats, sheep, donkeys, and, in some arid areas, camels), in an effort to keep our model simple and tractable we refer simply to "stock." Given that the Maasai economy is dominated by cattle, it would make the most sense for the reader to think of the "stock" in our model as cattle. During each time period, each actor's resource stock grew or shrank at a rate normally distributed around a mean of $3.4 \%$, a typical annual growth rate (Dahl and Hjort 1976). Maximum herd size was 600 , a realistic maximum herd size for an average sized household. During each period there was a chance that each herd would suffer a loss through drought or disease. As in Aktipis et al. (2011), we also ran additional simulations in which we varied the volatility size from zero to $50 \%$ and the volatility rate from zero to $20 \%$. Based on estimates of a family's caloric needs and productivity in the dry season (Dahl and Hjort 1976), we set the minimum size of a viable herd at 64 . Although this is high compared to the living standards of some Maa-speaking pastoralists (e.g., Cronk 2004), the exact number is not important so long as it is consistent across all conditions. Importantly, this figure is also consistent with Aktipis et al. (2011) (Fig. 1 and Appendix).

We then simulated account-keeping-based and need-based livestock transfers between individuals. In order to establish a baseline for comparison, we first ran simulations in which no transfers occurred. For runs involving the transfer of livestock, we simulated interactions among individuals of the same type as well as individuals of different types.

Below we describe the algorithms underlying need-based transfers and account keeping. Account keeping requires the tracking of debt and credit over time while need-based transfers require individuals only to know their own resource holdings.

Need-based transfer rules were implemented as follows (consistent with Aktipis et al. 2011):

1. Need-based asking rule: Individuals ask their partners for livestock only if their current holdings are below the asking threshold (i.e., the minimum stock size of 64).

2. Need-based giving rule: Individuals give what is asked, but not so much as to put their herds below the giving threshold (also the minimum stock size of 64). 
Fig. 1 Overview of model schedule. The full model schedule is included in the appendix

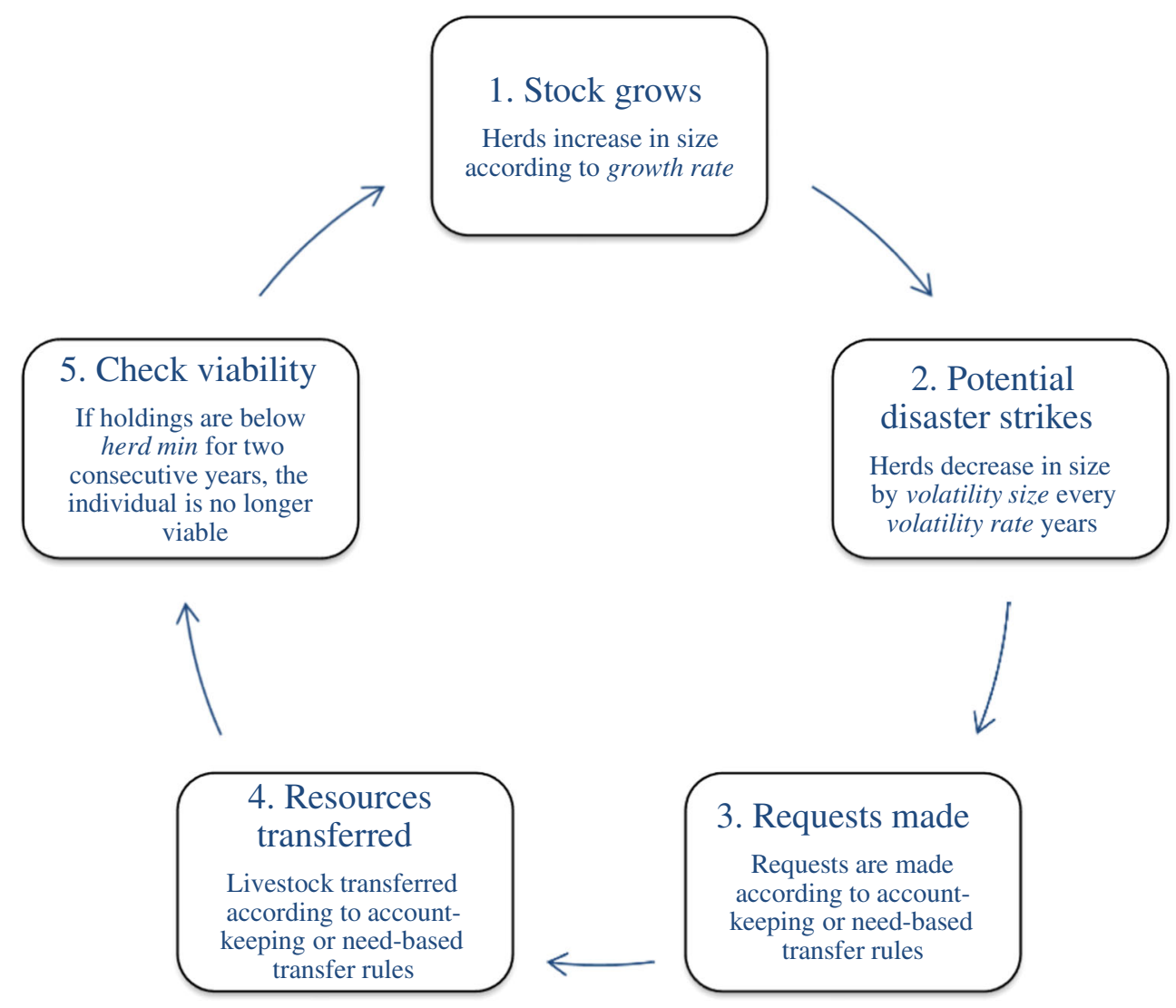

Account-keeping rules were implemented as follows:

\section{Account-keeping payback rule:}

a. If livestock have been previously transferred from the partner to the actor and the actor has enough to pay back without going below sustainability threshold (resource $\mathrm{min}$ ), the actor 'pays back' livestock to his partner according to the actor's repayment probability

2. Account-keeping partner credit check rule:

a. Checks whether partner is in good standing, which includes not having exceeded tolerated delay or credit size (when applicable)

\section{Account-keeping asking rule:}

a. As with the need-based transfer asking rule, individuals ask their partners for livestock if their current herd size is below the sustainability threshold of 64 .

\section{Account-keeping giving rule:}

a. Response to partner- If a request is made, actors give if two conditions are met: i. If no debt remains from a previous request and partner is in good standing (meaning that previous debt had not existed for longer than tolerated delay)

ii. The amount transferred cannot exceed the credit size extended to the partner

We then compared the performance of pairs of need-based transfer individuals with other types of pairs including no exchange pairs, account-keeping pairs and mixed pairs. Additional details regarding the model schedule, parameter values and model design can be found in the appendix.

\section{Results}

\section{Survival of Need-Based-Transfer Pairs vs. Account-Keeping Pairs}

We compared median survival of pairs of need-based transfer individuals, account-keeping individuals and no-exchange individuals under the ecological conditions specified in the model description. We found that pairs of need-based transfer individuals had higher rates of herd survival than account- 
keeping pairs or pairs in which partners did not transfer resources (Fig. 2).

\section{Correlations of Survival Durations Within Pairs}

In order to better understand whether individuals pool risk more effectively under need-based transfer rules than under account-keeping rules, we compared the median herd survival experienced by one individual in a simulation to that experienced by the other individual in the same simulation under four different conditions: (1) no exchange, (2) two accountkeeping agents, (3) one account-keeping and one need-based transfer agent, and (4) two need-based transfer agents (Fig. 3). We found no correlation between survival durations when individuals did not make transfers, but highly significant correlations between the fates of the individuals when they did transfer livestock. Specifically, when both individuals used need-based transfer rules, correlations of their survival were higher $(\rho=0.54)$ than when both individuals used accountkeeping rules $(\rho=0.40)$. This indicates that, in addition to being more effective than account-keeping at keeping livestock alive, need-based transfers also lead to a tighter yoking of the fates of the two parties in the risk-pooling relationship.

\section{Effects of Varying Environmental Volatility on Survival}

In our baseline model, the likelihood and severity of losses were normally distributed around $30 \%$ and $10 \%$, respectively. Given that the frequency of droughts in parts of East Africa has been increasing (Homann et al. 2008; Riché et al. 2009), we also looked at what happens when we vary the volatility size and volatility rate across simulations for pairs of accountkeeping individuals and pairs of need-based transfer individuals (Fig. 4). When volatility is very low, all individuals survive and when it is very high all individuals die. At all values located between those two extremes, need-based transfer individuals survive longer than account-keeping individuals.
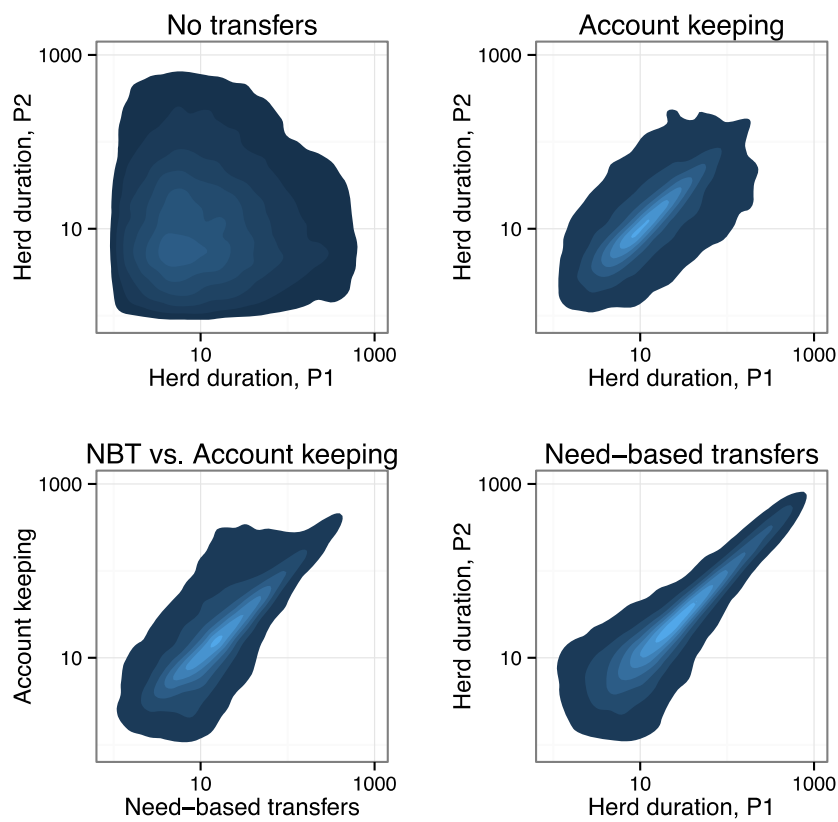

Fig. 3 Pairs of need-based transfer individuals (bottom right) show greater correlations of herd survival durations than account-keeping pairs, no-exchange pairs or mixed pairs. Spearman's rank correlations, $n=10,000$ per condition: no-transfer condition $\rho=-0.01$, n.s.; accountkeeping $\rho=0.40, \mathrm{p} \approx 0$; heterogeneous strategies $\rho=0.45, \mathrm{p} \approx 0$; needbased transfers $\rho=0.54, \mathrm{p} \approx 0$. $p$-values for all transfer conditions $<10^{-16}$

\section{Effects of Generosity on Survival}

In the osotua system, need-based transfers in their ideal form are always generous, i.e., individuals always give if they are asked and can do so without going below their own sustainability thresholds. We investigated whether the success of the need-based transfer rule was critically reliant on having $100 \%$ generosity (Fig. 5). We varied the generosity of need-based transfer individuals and account-keeping individuals to compare the viability of these strategies. For need-based transfer
Fig. 2 Need-based transfer pairs (red) show higher overall survival than account-keeping pairs (blue). Both need-based transfers and account keeping have higher survival than pairs in which no exchange occurs (green)

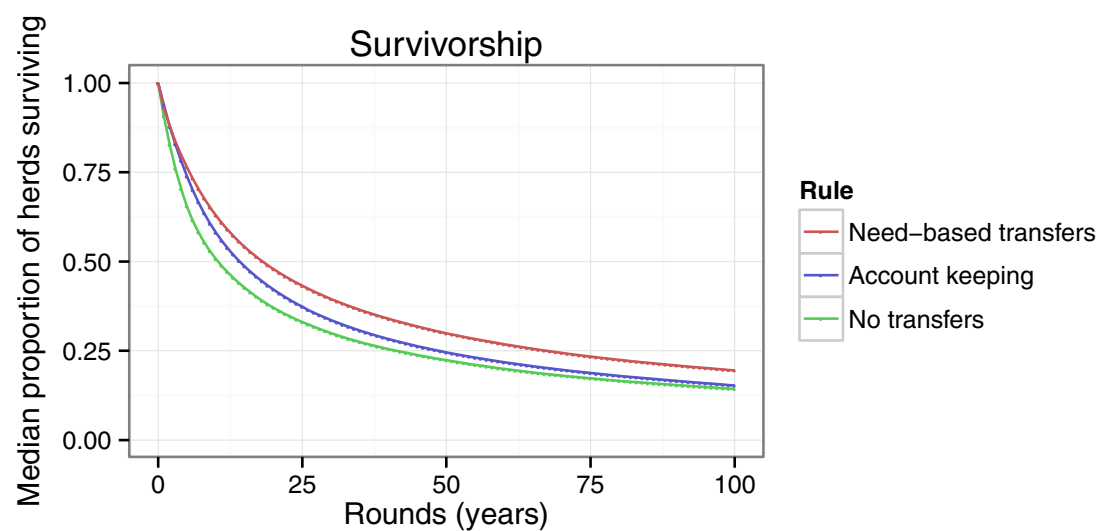


Fig. 4 a Need-based transfers outperform account keeping most clearly when volatility size is between $20-30 \%$ of total holdings. b Similarly, need-based transfers have the greatest advantage over account keeping when volatility rate is between 5 $10 \%$ per year. Shaded regions represent $95 \%$ confidence intervals

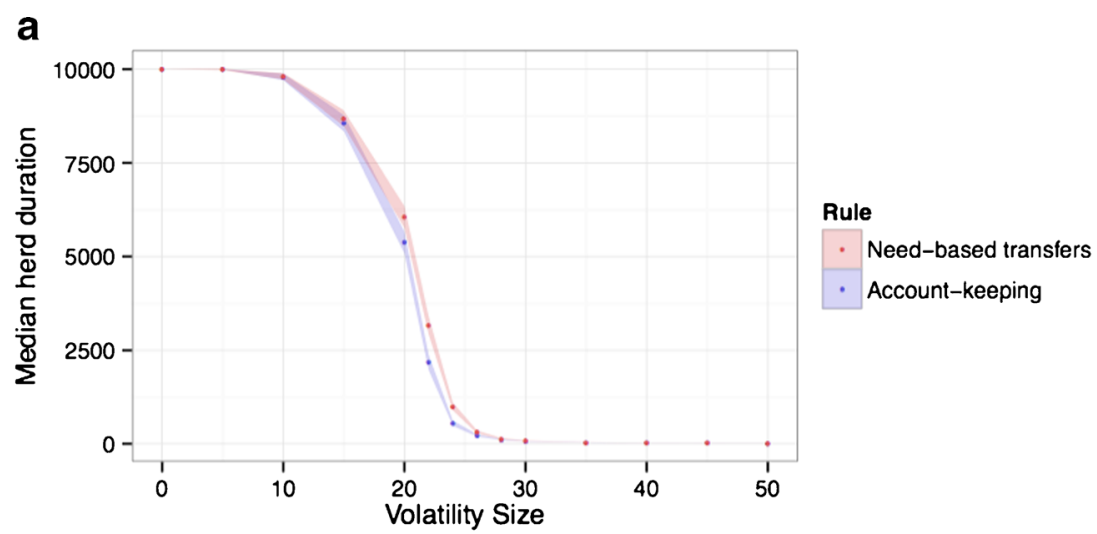

b

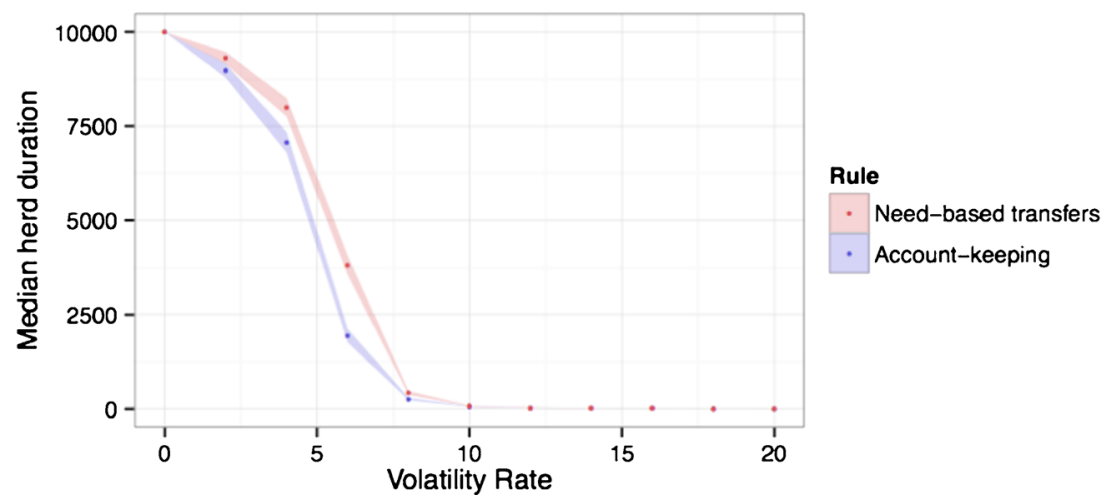

individuals, generosity was the likelihood of giving if asked and able. For account-keeping individuals generosity was the likelihood of giving to a partner in good standing if asked. We found (1) that neither the account-keeping rule nor the needbased transfer rule consistently outperforms no exchange unless generosity is at least $80 \%$ and (2) that, when generosity is high, pairs using the need-based transfer rule outperformed pairs using the account-keeping rule. Without generosity, need-based transfers are no more successful than account keeping.

\section{Survival in Mixed Pairs}

Under ecological conditions characterized by resource volatility, pairs using a need-based transfer strategy can outperform pairs using an account-keeping strategy. The relationship between the need-based transfer and account-keeping strategies is similar to the Stag Hunt Game (Skyrms 2003). Both strategies are coordination points, but two individuals using the need-based transfer strategy are likely to survive longer than two individuals using the account-keeping strategy (Fig. 6).
Fig. 5 Need-based transfer pairs outperform account-keeping pairs only when generosity is $80 \%$ or higher. Generosity is the likelihood of giving if asked by one's partner and one is able (need-based transfers) or to a partner in good standing (account keeping). Shaded regions represent $95 \%$ confidence intervals

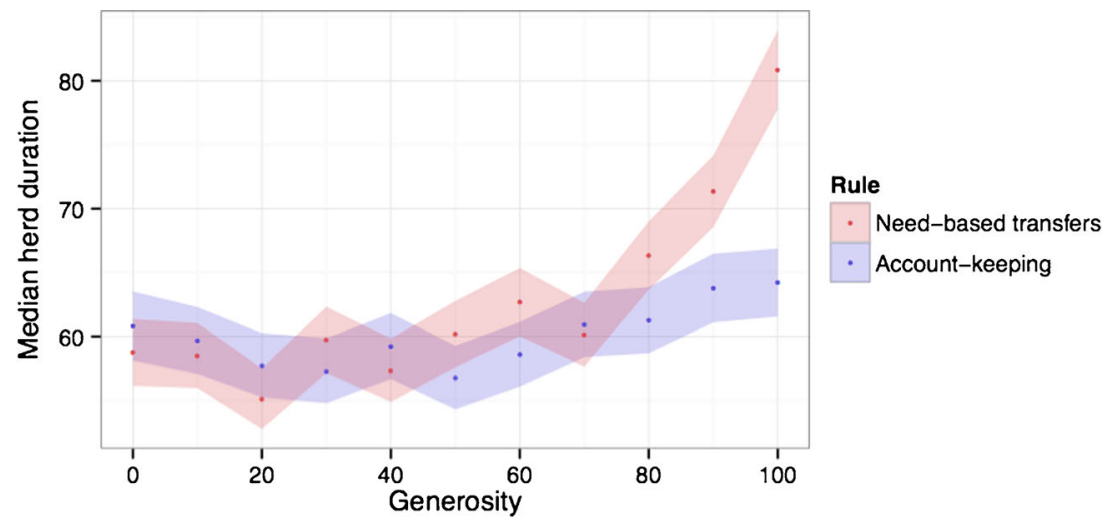




\begin{tabular}{|l|l|c|c|}
\hline & & \multicolumn{2}{|c|}{ Player 2 } \\
\hline & & Need-based & Account-keeping \\
\hline \multirow{3}{*}{ Player 1 } & Need-based & 30,30 & $23,29.5$ \\
\cline { 2 - 4 } & Account keeping & $29.5,23$ & 25,25 \\
\hline
\end{tabular}

Fig. 6 Payoffs in terms of survival at 50 years (in \%) for individual and partner using each rule in ecologically realistic environmental conditions. The need-based transfer strategy is dominant to the account-keeping strategy

The situation is thus a coordination problem that can be solved if all the individuals know both that there is a solution and that everyone involved also knows the solution (Chwe 2001; Cronk and Leech 2013). In the real world, common knowledge about need-based transfers can easily be provided by sharing norms such as the osotua concept that focus on the recipient's need rather than on debt and repayment.

\section{Wealth Inequality}

In our model, stochastic growth and volatility of resources create wealth inequality. Inequality is often measured using the Gini coefficient (Gini 1912), which varies from 0 (when wealth holdings are equal) to 1 (when one person controls all the wealth). For comparative purposes, the highest Gini coefficient in the world is currently 0.632 (Lesotho), and lowest is 0.230 (Sweden). The figure for the United States is 0.45 (Central Intelligence Agency 2013). We find that need-based transfer individuals have the lowest inequality compared to all other individuals (Fig. 7). Wealth inequality is highest in the absence of wealth transfers (.576), followed by accountkeeping individuals (.516), and need-based transfer individuals (.418). The Gini coefficient for need-based transfers (.418) is similar to that found for a sample of pastoralist societies $(.42 \pm .05)$ in a recent analysis of wealth inequality in societies with subsistence economies (Borgerhoff Mulder et al. 2009).

\section{Discussion}

Inspired by the Maasai osotua system, Aktipis et al. (2011) used an agent-based model to test whether a need-based transfer rule leads to risk pooling and enhanced survival in volatile ecological conditions. Here we extended this model to test whether need-based transfer rules also outperform accountkeeping in risky environments. We found that need-based transfers lead to greater risk pooling, longer survival and greater wealth equality than account-keeping, though both strategies outperformed scenarios involving no transfers of resources.

\section{Need-Based Transfers and Balanced Reciprocity}

Reciprocity has been an important topic in economic anthropology since the days of Malinowski (1922), Mauss (1967), and Polanyi (1957). A common framework for understanding different types of reciprocity is Sahlins' (1965) trichotomy of generalized, balanced, and negative reciprocity. Balanced reciprocity corresponds fairly closely with what we have been calling "account keeping." We chose "account keeping" over balanced reciprocity in order to emphasize and capture the importance of debt and repayment in Maasai esile transfers. Our focus has been on the contrasts between account-keeping reciprocity and need-based transfers. Both of these patterns may be adaptive responses to individual needs that are
Fig. 7 Stable differences in inequality exist between transfer strategies. Individuals engaging in no transfers (green) have the highest level of inequality, followed by account-keeping individuals (blue) and then dyads composed of need-based transfer individuals $(r e d)$. The straight line (gray) shows perfect equality

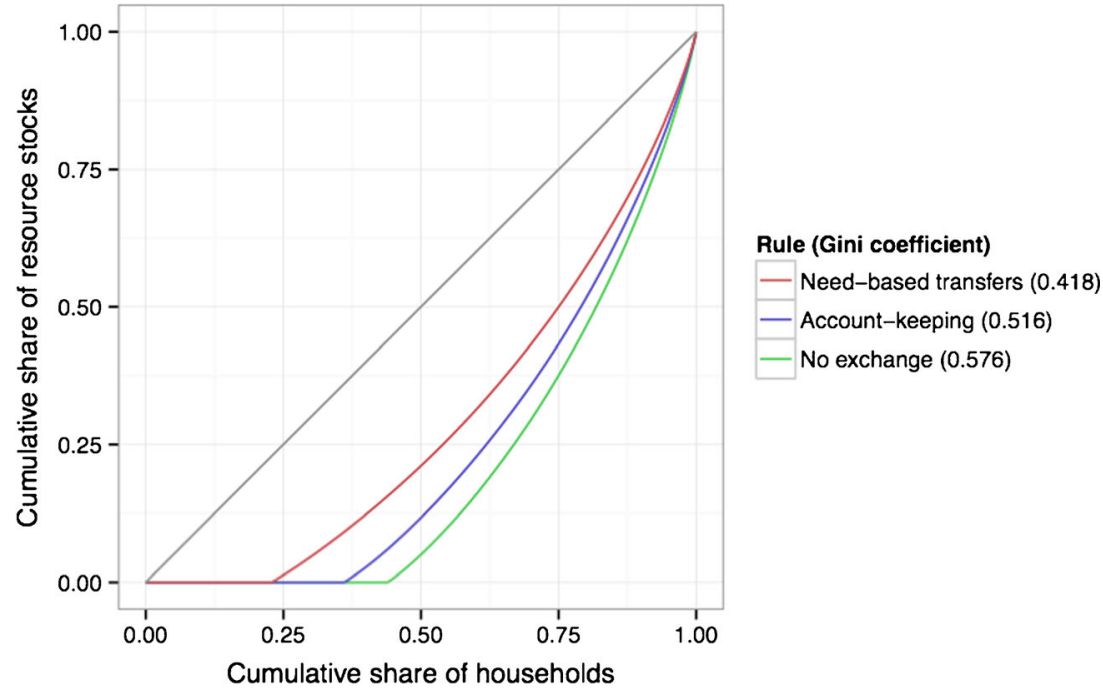


asynchronous among individuals. When individuals' needs all occur at the same time, neither account-keeping nor needbased transfers beyond close kin would likely be adaptive. But when needs arise asynchronously, it may make good adaptive sense for those with resources to transfer them to those without. The difference between need-based transfers and account-keeping becomes apparent when we consider the predictability of the needs in question. When needs are both asynchronous and highly predictable, account-keeping makes sense. If I know that I will always be in need on Tuesday and you know that you will always be in need on Friday, we can easily set up a system of balanced, tit-for-tat, account-keeping reciprocity that benefits us both. But if needs are not only asynchronous but also unpredictable, need-based transfers may, as our model suggests, make more adaptive sense than account-keeping. In short, when information about future needs is good, account-keeping may reign, while needbased transfers may prevail when such information is poor or nonexistent, as it was in our model. In developed economies, unpredictable needs are dealt with largely via formal insurance markets. Insurance companies overcome the problem of poor information about each individual's needs by gathering large amounts of data about needs (rates of car accidents, home fires, etc.) of many people. That allows them to focus on the accuracy of data about needs in the aggregate rather than on the inaccuracy of data regarding each individual's needs, which in turns allows them to set rates and engage in account-keeping exchanges with their clients (Levy 2012).

\section{Need-Based Transfers and Generalized Reciprocity}

In Sahlins' generalized reciprocity, sharing is indiscriminate and widespread. The same idea is also captured by Fiske's "communal sharing" (Fiske 1991). Generalized reciprocity and communal sharing are good descriptions of how resources are often shared within households and within hunter-gatherer bands (e.g., Howell 2010; Woodburn 1998; Price 1975). However, neither is an accurate description of osotua relationships or other stock friendship relationships among pastoralists. Such relationships are characterized not by indiscriminate and widespread sharing but rather by limited contractual commitments between individual livestock owners. The advantage of the phrase "need-based transfers" is that it captures both of these patterns, which focuses our attention on the fact that risk-pooling results from both of them. This, in turn, provides a link between the study of need-based transfers and the existing literatures on risk-pooling in both anthropology (Bird and Bird 1997; Bliege Bird et al. 2002; Cashdan 1985; Gurven et al. 2000; Gurven and Hill 2009, 2010; Wiessner 1982; Winterhalder 1986) and economics (e.g., Barr and Genicot 2008; Fafchamps and Lund 2003).

\section{Computational Simplicity of Need-Based Transfers}

In addition to its effectiveness in pooling risk, needbased transfer systems also have low cognitive load. Need-based transfer rules are simple: Ask if you need, give if you can. The rules underlying a tit-for-tat, account-keeping strategy can be straightforward in a Prisoner's Dilemma framework (Axelrod 1984), but they prove much more complex in the more realistic situation we sought to model. In contrast to the simple rules followed by the need-based transfer agents, the account-keeping agents must follow a complex set of rules regarding such issues as credit, debt and repayment. Account-keeping agents use memory of their past transactions with other agents, whereas need-based transfer agents simply need to keep track of whether their own resource holdings are above their survival threshold and occasionally calculate whether they can afford to help a partner in need. The low cognitive requirements of need-based transfer systems suggest that they may have predated account-keeping in our species' evolutionary history and could be more phylogenetically widespread than systems requiring account-keeping.

\section{Cheating and the Evolution of Cooperation}

Organisms who live socially have the ability to manage risk through risk pooling, enabling them to live in more challenging ecological conditions by sharing resources during times of need. However, as with other explanations for the evolution of cooperation, the problem of cheating must be addressed.

The vast literature on cheater detection and cheater suppression has largely been motivated by solving the problem of cheating in the context of account-keeping interactions (Cosmides and Tooby 1992; Van Lier et al. 2013). Cheating in the context of need-based transfer is different, however, from cheating in an account-keeping system. In an account-keeping system, cheating is typically a matter of not repaying one's debts. In a needbased transfer system, unbalanced accounts do not constitute cheating. Rather, cheating in a need-based transfer system involves asking for help when one is not in need or refusing to give when one is able. These different criteria for what constitutes cheating are another important way in which need-based transfers differ from account keeping.

Need-based transfers can be conceptualized as a form of decentralized and informal insurance. One of the problems that can arise when individuals have insurance in general is the problem of moral hazard, i.e., when individuals become more prone to take risks and act less carefully because they do not bear all the costs associated with a bad outcome. In this sense, the moral 
hazard problem may be at the heart of another way of cheating in a need-based transfer system: if being responsible and careful is costly, one can cheat by being lazy and taking unwise risks, knowing that one will receive help if the outcome is a severe loss or catastrophe. Interestingly, in the Maasai osotua system, individuals are also expected to act with responsibility, restraint and respect in how they handle their herds (Cronk 2007). In other words, they are expected to behave in such a way that may help to solve the moral hazard problem and minimize this type of cheating that is possible in systems of need-based transfers.

Another way of suppressing cheating is for individuals to carefully choose partners with whom they enter into need-based transfer relationships. Partner choice is one way of enhancing assortment of cooperators with one another, and it can be realized through both simple and complex rules for choosing and maintaining relationships (Aktipis 2004, 2006, 2011; Barclay 2013; Barclay and Willer 2007; Nesse 2009; Noe and Hammerstein 1994). Among the Maasai, need-based transfer relationships are taken very seriously and are said to be unbreakable once formed. Partner choice mechanisms could be at work in relationship formation if individuals can evaluate others through observing their behavior or reputations before entering into relationships in which they are committed to help. Choosing need-based transfer partners that have complementary risk profiles (i.e., independence of shocks) and responsible practices has high stakes. Discerning partner choice is therefore likely to play an important role in the viability of need-based transfer systems.

Need-based transfer systems require that individuals stay committed to helping a partner if that partner is unlucky; however, there may be conditions under which it is acceptable to terminate a need-based transfer relationship. These conditions may allow for dissolving relationships with greedy, stingy or irresponsible individuals (though not unfortunate ones). Relationship dissolution rules could thus provide another partner choice mechanism that could reduce cheating in need-based transfer systems. This is a research question that we will address in future fieldwork and modeling.

Finally, cheating in need-based transfer systems may be made difficult simply by the public nature of certain kinds of wealth. For example, among foragers, the same kinds of foods that are the most variable from day to day and the most likely to be widely shared (i.e., large game animals) are also the ones that are the most difficult to conceal. Among Maasai and other pastoralists, wealth primarily takes the form of livestock, whose visibility may make it difficult for anyone to feign either need or an inability to help. Despite the visibility of livestock, it would in principle be possible to hide one's wealth by taking advantage of practices such as enkitaaroto, a Maasai system in which animals are put in someone else's herd but without a transfer of ownership. We have livestock census data from two East African pastoralist societies, the Mukogodo Maasai of Kenya (Cronk 1989, 2004) and the Karimojong of Uganda. In both cases, the correlation between herders' apparent wealth, defined as the numbers of animals in their herds regardless of who really owns them, and actual wealth, defined as the number of animals that they actually own regardless of whose herd they happen to be in, is too high for this kind of cheating to be a problem (Mukogodo Maasai: Pearson's $\mathrm{r}=0.984$, $p<0.01, N=183$; Karimojong: Pearson's $\mathrm{r}=0.968$, $p<0.01, N=44)$. In systems where resources can be hidden or individuals are otherwise unable to evaluate the resource holdings of others, cheating in need-based transfer systems is likely to be a larger problem.

\section{Conclusion}

Effectively managing risk and uncertainty are recurring adaptive problems across human societies. One way of managing the risks associated with life in volatile ecologies is to pool risk with others. Here we show that need-based transfers outperform account-keeping rules and can be effective even when implemented in computationally simple terms.

Acknowledgments This material is based upon work supported by the National Science Foundation under Grant No. SES-0345945 to Arizona State University's Decision Center for a Desert City (DCDC) and Grant No. BCS-1324333 to Cronk and Iyer, National Institute of Health Grant No. F32 CA144331, and a grant from the John Templeton Foundation. We thank the Institute for Advanced Study in Princeton, the Center for Theological Inquiry in Princeton, the Center for Advanced Study in the Behavioral Sciences at Stanford University and the Wissenschaftskolleg in Berlin. We would also like to thank participants in the National Evolutionary Synthesis Center catalysis meeting for Synthesizing the Evolutionary and Social Science Approaches to Human Cooperation, the members of the Human Generosity Project and the members of the Cronk and Aktipis lab groups. Any opinions, findings, conclusions, or recommendations expressed in this material are those of the authors and do not necessarily reflect the views of the National Science Foundation (NSF), the National Institute of Health (NIH), or the John Templeton Foundation.

\section{Compliance with Ethical Standards}

Funding This material is based upon work supported by the National Science Foundation under Grant No. SES-0345945 to Arizona State University's Decision Center for a Desert City (DCDC) and Grant No. BCS-1324333 to Cronk and Iyer, National Institute of Health Grant No. F32 CA144331, and a grant from the John Templeton Foundation to Aktipis and Cronk.

Conflict of interests The authors declare that they have no conflicts of interest. 


\section{Appendix}

Model Description The model description offered below follows the standardized ODD protocol for describing individual and agent based models (Grimm et al. 2006) and is based on Aktipis et al. (2011).

Purpose Here we use an agent-based model of wealth transfers within ecologically realistic conditions to investigate the viability of two sets of cooperative rules: one characterized by account keeping and the other characterized by risk pooling norms of need-based transfers. We then investigate how these two rules affect overall resource stock survivorship and the variability of survivorship within dyads.

State Variables and Scales In this model time is represented discretely. Space is not explicitly modeled. Resource stock growth dynamics and volatility are implemented with global variables while the resource stock size and giving/asking rules are agent variables (Table 1). During each time period, agents execute the commands described in the schedule.

Process Overview and Scheduling This model proceeds in discrete time steps, and entities execute procedures according to the following ordering:

1. For each actor, resource stocks change in size:

a. Resource stocks increase in size according to growth rate

b. Resource stocks decrease in size by volatility size (as a percent of total holdings) according to volatility rate c. If resource stock size is above resource stock max it is set to resource stock max

d. Resource stock size is rounded to nearest integer

2. Requests are made:

- If giving is need-based, requests are made if resource stock size is below resource stock min

- If giving is account-keeping-based, requests are made if resource stock size is below resource stock min

3. Transfers are made:

- If giving is need-based, requests are fulfilled to the extent possible keeping the resource stock size of the giver above resource stock min

- If giving is account-keeping-based

- If resources have been previous transferred from the partner to the actor, the actor transfers net received resources to their partner according to repayment prob

- If a new request was made, actors give if two conditions are met

The debt has not existed for longer than tolerated delay

The amount transferred cannot exceed the credit size extended to the partner.

- All actors update net received to reflect transfers

4. Actors removed from the population if two consecutive rounds occur where resources holdings are below resource stock min.
Table 1 Overview of state variables associated with each entity

\begin{tabular}{|c|c|c|}
\hline Entity & State variable & Description \\
\hline \multirow[t]{5}{*}{ Global } & - Growth rate & Amount by which resource stocks grow each year \\
\hline & - Volatility rate & Likelihood of a negative event (e.g., drought) \\
\hline & - Volatility size & $\begin{array}{l}\text { Decrease in resource stock size resulting from negative } \\
\text { event }\end{array}$ \\
\hline & $\begin{array}{l}\text { - Min. resource stock } \\
\text { size }\end{array}$ & The minimum viable resource stock size \\
\hline & $\begin{array}{l}\text { - Max. resource stock } \\
\text { size }\end{array}$ & The maximum resource stock that can be maintained \\
\hline \multirow[t]{4}{*}{ Agents } & - Resource stock size & Number of resources in agent's resource stock \\
\hline & - Net received & Number of resources received minus given to partner \\
\hline & - Asking threshold & The threshold below which agents ask for resources \\
\hline & - Generosity & $\begin{array}{l}\text { The likelihood of giving if asked and able (need-based) } \\
\text { or giving to partner in good standing (account-keeping) }\end{array}$ \\
\hline Need-based only & - Giving threshold & $\begin{array}{l}\text { The threshold below which agents will no longer give } \\
\text { resources }\end{array}$ \\
\hline \multirow{4}{*}{$\begin{array}{l}\text { Account-keeping } \\
\text { only }\end{array}$} & - Credit size & The amount of credit granted to partner \\
\hline & - Tolerated delay & $\begin{array}{l}\text { The number of periods an agent will tolerate not being } \\
\text { repaid by partner before placing partner in bad standing }\end{array}$ \\
\hline & - P good standing & $\begin{array}{l}\text { If partner is in good standing, means that they have } \\
\text { not exceeded tolerated delay in past transfers }\end{array}$ \\
\hline & - Repayment probability & The likelihood of repaying partner during each time period \\
\hline
\end{tabular}


5. Age of actors incremented by 1

\section{Design Concepts}

Emergence In this model, risk pooling emerges from interactions between agents.

Prediction Agents in this model lack the ability to predict outcomes of future environmental variability or future social interactions. They do not integrate information across time periods.

Sensing Agents receive requests from their interaction partners and are able to examine their own resource holdings before fulfilling requests.

Interaction Agents interact by making and fulfilling requests for resources.

Stochasticity Resource stock growth and environmental volatility both have stochastic components.

Observation Reported data are averaged from 10,000 runs. Simulations were run until both agents were removed from the population (i.e., dropped below the viability threshold for more than 2 consecutive time periods).
Initialization All runs were initialized according to default parameters in the table below (Table 2).

Input In order to make our model of the Maasai pastoral system as realistic as possible, the following parameter values and assumptions about resource dynamics were based on existing scholarship (Dahl and Hjort 1976).

Growth rate We used a $3.4 \%$ growth rate with an SD of 2.53 based on Dahl and Hjort's (1976:66) estimate the growth rate in "normal" conditions to be $3.4 \%$, with a maximum possible growth rate of roughly $11 \%$ and a minimum of approximately $-6 \%$ (in the diminishing resource stocks example). Dahl and Hjort estimates are based on both empirical evidence and analytical modeling.

Resource stock size Initial resource stock sizes in our model were 70 , with a minimum of 64 and a maximum of 600 . These values were derived from Dahl and Hjort (1976:178) who state that a resource stock of 64 resources is sufficient to sustain a reference family. Resource stock sizes described in the text range from $60-100$ cows and resource stocks larger than 600 are not considered viable (Dahl and Hjort 1976:158).

Volatility We used a volatility rate of .1, meaning that on average a disaster (e.g., drought or disease) occurred every 10 years. In our model, this disaster reduced the resources resource stock by $30 \%$ on average, with a SD of $10 \%$. Dahl and Hjort (1976:114-130) note that these disasters occur approximately every $10-12$ years based on empirical data, and that the population decline (during disasters that occur every 10 years) should not be more than approximately $28 \%$, based on analytical models.

Table 2 Initial and default values for all variables

\begin{tabular}{|c|c|c|c|}
\hline Entity & State variable & Initial/Default value & Units \\
\hline \multirow[t]{5}{*}{ Global } & - Growth rate & $3.4(\mathrm{SD}: 2.53)$ & $\%$ current resource stock \\
\hline & - Volatility rate & 10 & $\%$ per year \\
\hline & - Volatility size & 30 (SD: 10) & $\%$ of current resource stock \\
\hline & - Min. resource stock size & 64 & Number resources \\
\hline & • Max. resource stock size & 600 & Number resources \\
\hline \multirow[t]{4}{*}{ Agents } & - Resource stock size & 70 & Number resources \\
\hline & - Net received & 0 & Number resources \\
\hline & - Asking threshold & 64 & Number resources \\
\hline & - Generosity & 100 & \% likelihood \\
\hline Need-based only & - Giving threshold & 64 & Number resources \\
\hline \multirow[t]{4}{*}{ Account-keeping only } & - Credit size & 5 & Number resources \\
\hline & - Tolerated delay & 5 & Years \\
\hline & - P good standing & Yes & Yes/No \\
\hline & - Repayment probability & 100 & $\%$ likelihood \\
\hline
\end{tabular}


Open Access This article is distributed under the terms of the Creative Commons Attribution 4.0 International License (http:// creativecommons.org/licenses/by/4.0/), which permits unrestricted use, distribution, and reproduction in any medium, provided you give appropriate credit to the original author(s) and the source, provide a link to the Creative Commons license, and indicate if changes were made.

\section{References}

Aktipis, C. A. (2004). Know When to Walk Away: Contingent Movement and the Evolution of Cooperation in Groups. Journal of Theoretical Biology 231(2): 249-260.

Aktipis, C. A. (2006). Recognition Memory and the Evolution of Cooperation: How Simple Strategies Succeed in an Agent-Based World. Adaptive Behavior 14: 239-247.

Aktipis, C. A. (2011). Is Cooperation Viable in Mobile Organisms? Simple Walk Away Rule Favors the Evolution Of Cooperation In Groups. Evolution and Human Behavior 32(4): 263-276 doi:10. 1016/j.evolhumbehav.2011.01.002.

Aktipis, C. A., Cronk, L., and de Aguiar, R. (2011). Risk-Pooling and Herd Survival: An Agent-Based Model of a Maasai Gift-Giving System. Human Ecology 39(2): 131-140.

Almagor, U. (1978). Pastoral Partners: Affinity and Bond Partnership Among the Dassanetch of South-West Ethiopia. Manchester Univ. Press, Manchester.

Axelrod, R. (1984). The Evolution of Cooperation. Basic Books, New York.

Barclay, P. (2013). Strategies for Cooperation in Biological Markets, Especially for Humans. Evolution and Human Behavior 34(3): 164-175 doi:10.1016/J.Evolhumbehav.2013.02.002.

Barclay, P., and Willer, R. (2007). Partner Choice Creates Competitive Altruism in Humans. Proceedings of the Royal Society B: Biological Sciences 274(1610): 749-753.

Barr, A., and Genicot, G. (2008). Risk sharing, commitment, and information: An experimental analysis. Journal of the European Economic Association 6(6): 1151-1185.

Bird, R. L. B., and Bird, D. W. (1997). Delayed Reciprocity and Tolerated Theft: The Behavioral Ecology of Food-Sharing Strategies. Current Anthropology 38(1): 49-78 doi:10.1086/204581.

Bliege Bird, R., Bird, D. W., Smith, E. A., and Kushnick, G. C. (2002). Risk and Reciprocity in Meriam Food Sharing. Evolution and Human Behavior 23(4): 297-321.

Bollig, M. (1998). Moral economy and self-interest: Kinship, friendship, and exchange among the Pokot (NW Kenya). In Schweizer, T., and White, D. (eds.), Kinship, Networks, and Exchange. Cambridge University Press, Cambridge. Cambridge University Press, Cambridge, pp. 137-157.

Bollig, M. (2010). Risk Management in a Hazardous Environment: A Comparative Study of Two Pastoral Societies (Vol. 2). Springer, New York.

Borgerhoff Mulder, B., Bowles, S., Hertz, T., Bell, A., Beise, J., Clark, G., et al. (2009). Intergenerational Wealth Transmission and the Dynamics of Inequality in Small-Scale Societies. Science 326(5953): 682-688.

Cashdan, E. A. (1985). Coping with Risk: Reciprocity Among the Basarwa of Northern Botswana. Man:454-474.

Central Intelligence Agency. (2013). The World Factbook. 2014, from https://www.cia.gov/library/publications/the-world-factbook/.

Chwe, M. S.-Y. (2001). Rational Ritual: Culture, Coordination, and Common Knowledge. Princeton University Press, Princeton, N.J.

Cosmides, L., and Tooby, J. (1992). In Barkow, J. H., Cosmides, L., and Tooby, J. (eds.), Cognitive Adaptations for Social Exchange. Oxford University Press, New York, pp. 163-228.
Cronk, L. (1989). The Behavioral Ecology of Change Among the Mukogodo of Kenya. Ph.D. dissertation, anthropology, Northwestern University, Evanston.

Cronk, L. (2004). From Mukogodo to Maasai: Ethnicity and cultural change in Kenya. Westview Press, Boulder.

Cronk, L. (2007). The Influence of Cultural Framing on Play in the Trust Game: A Maasai Example. Evolution and Human Behavior 28(5): 352-358.

Cronk, L., and Leech, B. L. (2013). Meeting at Grand Central: Understanding the Social and Evolutionary Roots of Cooperation, Princeton University Press.

Dahl, G., and Hjort, A. (1976). Having Herds: Pastoral Herd Growth and Household Economy. Dept. of Social Anthropology, University of Stockholm, Stockholm.

Dorfman, M. S. (2007). Introduction to Risk Management and Insurance, Prentice Hall.

Dyson-Hudson, N. (1966). Karimojong Politics. Clarendon, Oxford.

Fafchamps, M., and Lund, S. (2003). Risk-sharing networks in rural Philippines. Journal of Development Economics 71: 261-287.

Fiske, A. P. (1991). Structures of Social Life: The Four Elementary Forms of Human Relations. Free Press, New York.

Flannery, K., Marcus, J., and Reynolds, R. (1989). The Flocks of the Wamani: A Study of Llama herders on the Punas of Ayacucho, Peru. Academic, New York.

Gini, C. (1912). Variabilità e mutabilità. In P. E., and Salvemini T (eds.), Reprinted in Memorie di metodologica statistica. Libreria Eredi Virgilio Veschi, Rome (1955).

Grimm, V., Berger, U., Bastiansen, F., Eliassen, S., Ginot, V., Giske, J., Goss-Custard, J., Grand, T., Heinz, S., and Huse, G. (2006). A Standard Protocol For Describing Individual-Based and AgentBased Models. Ecological Modeling 198: 115-126.

Gulliver, P. (1955). The Family Herds: A Study of Two Pastoral Tribes in East Africa: the Jie and Turkana. International Library of Sociology and Social Reconstruction.

Gurven, M., Allen-Arave, W., Hill, K., and Hurtado, M. (2000). "It's a Wonderful Life": Signaling Generosity Among the Ache of Paraguay. Evolution and Human Behavior 21(4): 263-282.

Gurven, M., and Hill, K. (2009). Why Do Men Hunt? Current Anthropology 50(1): 51-74.

Gurven, M., and Hill, K. (2010). Moving Beyond Stereotypes of Men's Foraging Goals. Current Anthropology 51(2): 265267.

Homann, S., Rischkowsky, B., Steinbach, J., Kirk, M., \& Mathias, E. (2008). Towards endogenous livestock development: Borana pastoralists' responses to environmental and institutional changes. Human Ecology 36(4): 503-520.

Homewood, K. (2008). Ecology of African Pastoralist Societies. Oxford.

Howell, N. (2010). Life Histories of the Dobe !Kung. University of California Press, Berkeley.

Levy, J. (2012). Freaks of Fortune: The Emerging World of Capitalsim and Risk in America. Harvard University Press, Cambridge.

Malinowski, B. (1922). Argonauts of the Western Pacific. Routledge, London.

Mauss, M. (1967). The gift: Forms and functions of exchange in archaic societies. Norton, Trans. Ian Cunnison. New York.

Mol, F. (1996). Maasai Language and Culture Dictionary. Maasai Centre, Lemek.

Nesse, R. M. (2009). Runaway Social Selection for Displays of Partner Value and Altruism. In Verplaetse, J., De Schrijver, J., Vanneste, S., and Braeckman, J. (eds.), The Moral Brain. Springer, Netherlands, pp. 211-231.

Noe, R., and Hammerstein, P. (1994). Biological Markets: Supply and Demand Determine the Effect of Parner Choice in Cooperation, Mutualism and Mating. Behavioral Ecology and Sociobiology 35: $1-11$. 
Perlov, D. C. (1987). Trading for influence: The social and cultural economics of livestock marketing among the highland Samburu of Northern Kenya. Ph.D. dissertation, anthropology, University of California - Los Angeles.

Polanyi, K. (1957). The great transformation. Beacon Press, Boston.

Price, J. A. (1975). Sharing: The integration of intimate economies. Anthropologica 17(1): 3-27.

Riché, B., Hachileka, E., Awuor, C. B., \& Hammill, A. (2009). Climaterelated vulnerability and adaptive capacity in Ethiopia's Borana and Somali communities. IISD report.

Sahlins, M. (1965). On the sociology of primitive exchange. In Banton, M. (ed.), The Relevance of Models for Social Anthropology. Tavistock. Reprinted in Stone Age Economics, London (1972, Transaction).

Skyrms, B. (2003). The Stag Hunt and the Evolution of Social Structure: Cambridge University Press.
Van Lier, J., Revlin, R., and De Neys, W. (2013). Detecting Cheaters Without Thinking: Testing the Automaticity of the Cheater Detection Module. PLoS One 8(1): e53827 doi:10.1371/journal. pone.0053827.

Wiessner, P. (1982). Risk, reciprocity and social influences on! Kung San economics. In Leacock, E., and Lee, R. (eds.), Politics and History in Band Societies (Vol. 61). Cambridge University Press, Cambridge, pp. 61-84.

Winterhalder, B. (1986). Diet Choice, Risk, and Food Sharing in a Stochastic Environment. Journal of Anthropological Archaeology 5(4): 369-392.

Woodburn, J. (1998). Sharing is not a form of exchange: An analysis of property-sharing in immediate-return hunter-gatherer societies. In Hann, C. M. (ed.), Property Relations: Renewing the Anthropological Tradition. Cambridge University Press, Cambridge, pp. 48-63. 